\title{
SOBRE A NATUREZA DA INFERÊNCIA EM BOGHOSSIAN
}

\author{
On the nature of inference in Boghossian
}

Sobre la naturaleza de la inferencia de Boghossian

Doraci Engel ${ }^{1}$

Porto Alegre, RS Brasil.

\section{Resumo}

Se crer com base em razões é algo que aparentemente envolve passos e toma tempo, o que nos previne de considerar o julgamento inferencial ou o raciocínio de um modo geral como uma atividade, o produto de um tipo especial de agência? A ideia de que há atividade genuína quando realizamos uma inferência está implícita em vários autores. Neste artigo analiso uma defesa explicita desta concepção: a tese desenvolvida por Paul Boghossian de que a inferência é uma forma de ação cognitiva. Argumento que há um contraste na estrutura das razões e de causação entre crer por razões e agir por razões. E concluo que o que parece ser ativo no caso específico de raciocínio, que é fazer uma inferência, deve-se a sua conexão conceitual com o estado de crença. Quando cremos que $\mathrm{p}$ com base em q, cremos por uma razão que nos é dada por outra crença. Palavras-chave: Inferência. Agência. Crença. Causação racional. Boghossian.

\footnotetext{
Abstract

If believing based on reasons is something that apparently involves steps and takes time what prevents us from considering inferential judgment or reasoning in general

Doutor em Filosofia pela Pontifícia Universidade Católica do Rio Grande do Sul (PUCRS). ORCID: http://orcid.org/0000-0002-4700-0791.E-mail: doraci.engel@gmail.com
} 
as an activity, the product of a special kind of agency? The idea that there is genuine activity when we make an inference is implicit in many authors. In this paper I analyze an explicit defense of this conception: the thesis developed by Paul Boghossian that inference is a form of cognitive action. I argue that there is a contrast in the structure of reasons and causation between believing for reasons and acting for reasons. And I conclude that what seems to be active in the specific case of reasoning which is to make an inference is due to its conceptual connection with the state of belief. When we believe that $\mathrm{p}$ based on $\mathrm{q}$, we believe for a reason given to us by another belief.

Keywords: Inference. Agency. Belief. Rational Causation. Boghossian.

\section{Resumen}

¿Si creer en la base de razones es algo que al parecer involucra pasos y toma tiempo que nos previne de considerar el juicio inferencial o razonamiento en general como una actividad, el producto de un tipo especial de agencia? La idea de que hay actividad genuina cuando realizamos una inferencia está implícita en varios autores. En este artículo analizo una defensa explícita de esta concepción: la tesis desarrollada por Paul Boghossian de que la inferencia es una forma de acción cognitiva. Sostengo que hay un contraste en la estructura de las razones y la causalidad entre creer por razones y actuar por razones. $Y$ concluyo que lo que parece estar activo en el caso específico del razonamiento, que es hacer una inferencia, se debe a su conexión conceptual con el estado de creencia. Cuando creemos que en p base en q, creemos que por una razón que se da por otra creencia.

Palabras clave: Inferencia. Agencia. Creencias. Causalidad racional. Boghossian.

\section{Introdução}

Afinal, o que acontece quando inferimos, quando cremos que q porque cremos que p?² Para Boghossian inferir é uma ação mental de "nível pessoal, consciente, voluntária" (BOGHOSSIAN, 2014, p. 3). Valendo-se da classificação de Daniel Kahneman (2011) em psicologia cognitiva,

\footnotetext{
2 A pergunta aqui não é sobre o que intitula alguém a inferir. Seguindo a sugestão de Boghossian, nosso tópico é a natureza da própria inferência. Não me envolverei com as diferentes explicações que consideraram a capacidade de inferir como um tipo de conhecimento. Isto porque saber fazer uma inferência, embora faça diferença naquilo que uma pessoa pode fazer, não explica a suposta atividade que é fazer uma inferência.
} 
ele sustenta que inferir é algo que ocorre no que Kahneman chama de “Sistema 2" de raciocínio. Diferentemente do "Sistema 1", que opera em nível subpessoal, automática, rápida e involuntariamente, o "Sistema 2" mobiliza atenção, esforço e um conjunto de atividades mentais. Na sua visão e de muitos outros ${ }^{3}$ é exatamente a operação desse mecanismo natural que nos permite ter a experiência subjetiva de agência, como algo que envolve escolha e controle de nossa parte.

Assim como Ernest Sosa, Boghossian reconhece que pode haver algum tipo de agência funcional quando raciocinamos no âmbito do "Sistema 1". É o que ocorre quando manifestamos o que Sosa chama de "conhecimento animal" (SOSA, 2009). Mas também como Sosa, ele pensa que não é isso que os filósofos têm em mente quando se referem a termos como julgar e inferir. Ele argumenta que embora muitas vezes nosso raciocínio possa parecer automático e imediato, fazer uma inferência é algo que pertence ao "Sistema 2" ou, no mínimo, a um tipo de operação intermediária, relativamente automática, que não exige muita atenção. "[...] um Sistema 1.5 para cima, talvez" (BOGHOSSIAN, 2014, p. 2).

Inferir, na visão de Boghossian, é um processo de seguir certas regras de raciocínio na qual um agente extrai conclusões de premissas. O caráter ativo desse processo decorre do que ele chama de "Taking Condition" (condição de tomar, adotar ou assumir uma determinada atitude). "Inferir envolve necessariamente o sujeito tomar suas premissas para suportar sua conclusão extraindo suas conclusões por causa deste fato" (BOGHOSSIAN, 2014, p. 4, grifos do autor).

Assim, usando o exemplo do próprio Boghossian, quando um sujeito $S$ (1) crê que choveu na última noite, e (2) se choveu na última noite, as ruas estão molhadas, (3) as ruas estão molhadas o que ocorre é que suas duas crenças-premissas estão causando sua crença-conclusão. Porém, como nem todo processo causal no qual duas crenças causam uma terceira é

3 Ver, por exemplo, Ernest Sosa sobre a noção de "crença apta" (SOSA, 2009). 
um caso de raciocínio, o desafio de Boghossian é justamente separar os casos de raciocínio do que ele chama de "mera causação" (um estado de crença causando outro estado de crença). Como ele escreve:

A intuição por trás (desta) Taking Condition é que nenhum processo causal conta como inferência, a menos que ele consista em uma tentativa de alcançar uma crença através de descobrir o que, em algum sentido amplo adequado, é suportado por outras coisas que alguém crê. No sentido relevante, raciocínio é algo que nós fazemos, não algo que apenas acontece conosco (BOGHOSSIAN, 2014, p. 5, grifo do autor).

Em resumo, o que Boghossian parece postular na passagem acima é que inferir é um tipo de atividade - uma atividade intencional que remete a um tipo relevante de agência. Trata-se de uma proposta controversa e, eventualmente, implausível se consideramos a visão prevalente na filosofia da ação, segundo a qual a noção básica de atividade está conectada necessariamente ao conceito de ação. Ou seja, um agente está engajado em atividade somente na medida em que uma ação de sua parte está ocorrendo. E ações, na assim chamada "estória padrão da ação", são "eventos" causados por estados mentais e outros eventos, como veremos a seguir. ${ }^{4}$

\section{A narrativa padrão da ação}

Ao afirmar que inferir é uma ação mental de "nível pessoal", "consciente" e "voluntária", Boghossian compartilha uma concepção semelhante ao que

\footnotetext{
4 De acordo com essa visão, difundida originalmente a partir de Donald Davidson (1963), agentes são sujeitos de predicações de eventos. Para uma crítica a essa narrativa padrão ver Michel Thompson (2008) para quem ações são mais bem explicadas não por sua relação causal com estados mentais e eventos, mas pelos eventos ou processos que as constituem. A questão sobre se as razões de um agente para agir são as causas da ação está no centro de múltiplos debates em filosofia da mente e filosofia da ação. Não farei essa discussão aqui. Apenas assumirei, com a literatura e sem argumentação adicional, a visão dominante. Ou seja, a concepção de que a explicação das razões na explicação de uma ação deve ser, de algum modo, uma explicação causal.
} 
alguns autores chamam de "agência humana por excelência" (VELLEMAN, 1992; O'BRIEN, 2007). De acordo com essa visão, um agente realiza uma ação, se ele faz $\phi$ "intencionalmente", "têm razões" para $\phi$, pode ser "reflexivamente consciente" de $\phi$, é "livre" para fazer $\phi$ e, assim, é "responsável" por fazer $\phi$. A essas condições costuma-se adicionar a exigência, conhecida como cláusula causal, de que a relação entre a intenção para fazer $\phi$ e a ação de fazer $\phi$ seja de causação pelos estados mentais do agente.

A despeito dos problemas que o modelo acima pode apresentar, penso que ele reflete adequadamente o que em geral se considera serem a concepção e a teoria padrão da ação humana. Trata-se de uma visão que concebe a ação em termos de intencionalidade (ANSCOMBE, 1957; DAVIDSON, 1963) e que explica a intencionalidade com uma teoria da ação em termos de causação pelos estados mentais do agente e eventos (DAVIDSON, 1963, 1981; GOLDMAN, 1970; MELE, 2003).

Donald Davidson (1980) afirma que uma ação, em um sentido básico, é algo que um agente faz que é "intencional sob alguma descrição", sugerindo que há uma relação conceitual entre ação genuína, de um lado, e intenção, de outro. Não pretendo explorar aqui as várias inflexões que esses dois conceitos têm na literatura. Também não irei me envolver com as dificuldades notórias de como individuar uma ação que é intencional sob uma descrição e não sob outra. Nem tampouco tomar partido no debate se as razões do agente em agir são, de fato, as causas da ação. Assumirei, com a maioria, que explicar ações em termos de intencionalidade e intencionalidade em termos de causação racional ainda é a abordagem mais plausível para entendermos a ação humana.

Basicamente, o que o modelo padrão de ação nos ensina é que uma ação, para ser uma ação e não algo que apenas acontece conosco, deve ser racional. Ou seja, não basta que haja uma sequência causal de eventos que produz certo movimento corporal. É necessário que o evento seja produ- 
zido por uma razão. É o que Davidson chama de intenção "com a qual" o evento é produzido que irá assegurar que a causação obedeça a rota certa 5 .

\section{O problema do regresso de razões}

Independentemente de tomarmos razões como estados mentais ou fatos, a relação "ser uma razão para $x$ fazer $\psi$ " está relacionada ao que a literatura epistemológica define como relação de "embasamento" (basing relation) entre uma razão e uma crença, no sentido de algo "ser uma razão para S crer que p". Trata-se de uma relação que é definida usualmente em termos causais, discutida na filosofia da ação sob a rubrica de "razões explicativas". A crença de $S$ que $\phi$ é baseada na crença de $S$ que $\psi$ quando a última causa ou é causalmente sustentada pela primeira de modo apropriado. ${ }^{6}$

Como na teoria da ação, na teorização sobre a relação de embasamento epistêmico costuma-se fazer uma distinção entre algo ser uma razão para crer e a razão pela qual se crê. De tal modo, que uma crença C será apropriadamente baseada em uma razão $R$, somente se $R$ suportar racionalmente $\mathrm{C}$ e $\mathrm{R}$ explicar porque $\mathrm{C}$ é sustentada. Há várias teorias sobre o que é para uma crença ser baseada em uma razão. As que me interessam aqui são as que preservam a visão tradicional de justificação epistêmica e, mais particularmente, de justificação doxástica, como algo necessário para o conhecimento. Para S conhecer que $\mathrm{p}$, além de crer que

\footnotetext{
5 Rota certa diz respeito ao problema da causação desviante. Muito resumidamente, é o problema de que sempre parece possível que os estados mentais relevantes e eventos causem o evento ou ação relevante (certo movimento corporal, por exemplo) de um modo que não corresponde à intenção do agente. As razões que causam a ação são diferentes da intenção. Como mostra o famoso exemplo de Davidson. O montanhista segura o companheiro de escalada na corda. O companheiro está solto no ar e há o risco de os dois despencarem. O montanhista avalia a situação e forma a intenção de se livrar do peso excessivo soltando a corda que os une. Esse pensamento o deixa nervoso e o nervosismo o faz soltar a corda (DAVIDSON, 1973). O que esse caso mostra é que há uma lacuna entre a intenção do montanhista e o seu comportamento. Seu comportamento não é causado por sua intenção seguindo a rota causal apropriada. Ele é causado pelo nervosismo e, por isso, não pode ser considerado uma ação.
}

6 Novamente, modo apropriado aqui diz respeito ao problema das cadeias causais desviantes referido acima. 
$p$ e ter suficientes boas razões epistêmicas para crer que $p, S$ deve crer que $\mathrm{p}$ com base nessas boas razões?

Assim, quando afirmamos que $\mathrm{S}$ crê "racionalmente" que $\phi$ queremos dizer que há boas razões epistêmicas para crer que $\phi$ e que $S$ crê que $\phi$ com base nessas razões ${ }^{8}$. Formulada desta maneira, a relação de embasamento parece contemplar a cláusula causal, prevista no modelo padrão de ação intencional descrito acima. $\mathrm{E}$, ao mesmo tempo, preserva a noção de justificação doxástica9. Digo "parece" porque o que esta formulação sugere é que há uma analogia entre o que justifica uma ação e o que justifica uma crença.

Como ensina Dadvison, uma sucessão de eventos somente será uma ação se ela for causada apropriadamente. Isto é, se ela for causada por uma razão, que não é qualquer razão disponível ao agente, mas a razão pela qual a ação é produzida. Similarmente, para ser justificada ou racional, uma crença deve estar apropriadamente baseada em uma razão, que não pode ser qualquer razão, mas a razão que a justifica ou racionaliza.

Há várias maneiras de se formular essa analogia. Pode-se dizer, por exemplo, que $S$ crê racionalmente que $\phi$ em um tempo t, se $S$ crê racionalmente que $\phi$ em virtude do fato de que sua crença é baseada em boas razões em $\mathrm{t}$. Ou simplesmente que $\mathrm{S}$ crê que $\phi$ porque $\mathrm{S}$ tem boas para razões para crer que $\phi$. Ou ainda que há boas razões para crer que $\phi \mathrm{e}$ essas são as razões porque $\mathrm{S}$ crê que $\phi$ e assim por diante.

\footnotetext{
7 É importante notar que a relação de embasamento epistêmico é necessária, porém não suficiente para a justificação epistêmica, seja qual for a teoria. Trata-se de uma relação que se verifica mesmo quando o agente não tem boas razões epistêmicas para crer.

8 Utilizarei os conceitos de racionalidade e justificação com o mesmo sentido, distinguindo apenas as noções de racionalidade ou justificação epistêmica (que se aplica às crenças) e racionalidade ou justificação prática (que se aplica às ações).

9 A posição mais difundida na literatura contemporânea estabelece que conhecimento requer justificação doxástica e não meramente justificação proposicional. A justificação doxástica ocorre quando o agente crê algo para o qual ele tem justificação proposicional e baseia sua crença naquilo que proposicionalmente a justifica. Em outras palavras: não basta ter disponível boas razões para crer. Para conhecer também é necessário ser capaz de estabelecer a conexão, crendo com base nestas boas razões. Para uma análise mais detalhada das diferenças entre justificação proposicional e justificação doxástica ver TURRI (2010).
} 
Porém, seja qual for a formulação da relação de embasamento que se queira empregar aqui, ela irá enfrentar uma dificuldade comum às atribuições de racionalidade de caráter doxástico. Isto é, das atribuições que dizem respeito ao suporte evidencial ou a racionalidade da crença. Refiro-me a um tipo familiar de regresso de razões que ocorre quando, em um contexto dialógico, o sujeito é desafiado a apresentar uma meta-crença apropriada que assegure que sua razão é uma boa para razão para sustentar sua crença. É quando nos damos conta que a justificação das boas razões da crença de $S$ está na dependência das razões ostentadas por outras crenças de S (meta-crenças), que, por sua vez, dependem das boas razões de outras crenças e, assim, infinitamente.

\section{A solução de Boghossian: seguir regras}

Teorias doxásticas da relação de embasamento epistêmico partem do pressuposto de que ter uma meta-crença apropriada sobre o que é uma boa razão para uma crença é suficiente para que a crença seja baseada apropriadamente nesta razão. No caso específico da inferência seria uma meta-crença sobre a relação entre premissas e conclusão (que o julgamento das premissas confira justificação para crer na conclusão). Boghossian argumenta, entretanto, que quando alguém realiza uma inferência, ele não precisa necessariamente de uma meta-crença sobre a relação entre suas premissas e sua conclusão. Ele poderia seguir regras inferenciais sem que isso tenha que ser um estado intencional, cujo conteúdo diz respeito à relação entre as premissas da inferência e sua conclusão. Voltarei a esse ponto mais adiante.

De acordo com Boghossian, a Taking Condition deve ser entendida como requerendo que o agente aplique uma regra de raciocínio que ele aceita e que esta regra o autorize a fazer a inferência. Ou seja, se alguém seguir a regra de fazer $\phi$ na circunstância $C$, então ele toma a ocorrência de $C$ como sendo uma razão para fazer $\phi$. Já no análogo epistêmico isto significa que se alguém segue uma regra ao inferir $q$ de $p$, ele toma $p$ como sendo uma razão para crer q. E mais: ele crê q por isso. 
Estamos tentando explicar o que é para alguém tomar (1) ["Choveu na noite passada"] e (2) ["Se choveu na noite passada, então as ruas estão molhadas"] para justificar (3) ["As ruas estão molhadas"]. E nossa ideia é que esse tomar pode ser entendido como uma questão de a pessoa aplicar uma regra que ela aceita, Modus Ponens, aos conteúdos (1) e (2) derivando deles a conclusão (3) e assim vindo a crer nela (BOGHOSSIAN, 2014, p. 15).

Há, entretanto, um problema potencial com esta proposta. Aplicada ao modelo de inferência sugerido por Boghossian, a dificuldade remete ao famoso problema cético de seguir regras, que ocorre quando consideramos, como muitos filósofos, que seguir regras deve envolver um conteúdo intencional..$^{10}$ Trata-se de um regresso vicioso que, no caso especifico da suposta ação epistêmica, que é fazer uma inferência, pode ser percebido com a combinação de apenas duas premissas:

\section{i. Toda inferência é uma forma de seguir-regras, e \\ ii. Seguir regras envolve inferência.}

Pensando em nível pessoal (o regresso ocorre também quando consideramos inferência em termos subpessoais ${ }^{11}$ ) isso equivaleria a dizer

\footnotetext{
10 Refiro-me à leitura de Saul Kripke, endossada por Boghossian, sobre o problema inaugurado por Wittgenstein (Kripke, 1982 apud Boghossian [2008]). Resumidamente, Kripke coloca o problema da seguinte forma: "Para seguir regras, teríamos que previamente ter intenções. Para ter intenções, as expressões da nossa linguagem de pensamento teriam que ter significado. Para essas expressões terem significado, teríamos que usá-las de acordo com regras. Para usá-las de acordo com regras, teríamos que previamente ter intenções. E assim por diante, ad infinitum.

$"$ Para Boghossian apelar para o nível subpessoal, em que a conclusão simplesmente aparece na nossa mente como o resultado de uma função automática, subconsciente, não irá resolver o problema do regresso. Isto porque a racionalidade requer que nos perguntemos se realmente devemos endossar a conclusão ou não. E, ao fazer isso, ele explica, temos que nos tornar conscientes da inferência voltando, assim, ao nível pessoal. Além disso, mesmo que nos mantenhamos no nível subpessoal, inferir requer um estado intencional (representacional) na qual os requerimentos das regras que estamos seguindo estejam codificados. Porém, de novo, veríamos que alguma inferência (agora subpessoal) seria requerida para descobrirmos o que a regra pede sob àquelas circunstâncias e, assim, infinitamente.
} 
que seguir regras envolve transições inferenciais entre estados mentais (intenções e aceitações "explicitas") que, por sua vez, carregam o conteúdo das regras que o indivíduo em questão está seguindo ${ }^{12}$. Isto porque as intenções e as aceitações explicitas aqui são justamente a intenção de seguir uma regra ou a aceitação explicita de seguir uma regra.

Como explica Crispin Wright: para seguir uma regra $\mathrm{R}$ em uma ocasião específica, o sujeito deve, por (ii), se mover inferencialmente de um estado mental que carrega o conteúdo de R (inferência1). Para fazer essa inferência ele deve, por (i), seguir uma regra apropriada de inferência. $E$, assim, por (ii), fazer uma inferência2 do estado que carrega o conteúdo desta regra de inferência. Essa inferência2, por sua vez, deve por (i) envolver um episódio de seguir regras, e, assim, deve envolver por (ii), uma inferênciaz de um estado mental que carrega o conteúdo da(s) norma(s) relevante(s) ... (WRIGHT, 2014, p. 30) ${ }^{13}$.

Assim como rejeita uma concepção de racionalidade baseada em operações no nível subpessoal, Boghossian também recusa a análise disposicional de seguir regras, adotada, por exemplo, por John Broome. ${ }^{14}$ Muito resumidamente, de acordo com essa visão, poderíamos seguir uma regra sem a necessidade de estados intencionais. Assim, para explicar o que é seguir uma regra $R$ bastaria que nossas disposições se conformassem à regra R sob circunstâncias apropriadas. Assim, $\mathrm{S}$ segue R se $\mathrm{S}$ está disposto a se conformar à $\mathrm{R}$ sob condições apropriadas ideais.

Independentemente de qualquer outra razão, o fato é que as abordagens que tratam a racionalidade como a manifestação de uma disposição de seguir regras não servem ao propósito de Boghossian. Isto porque se a manifes-

\footnotetext{
12 Estou me referindo à intenção de seguir regras e de aceitação explicita de seguir regras, porque é isso que ocorre nos casos ordinários de ação intencional.

13 O regresso é infinito porque cada inferência tem uma conclusão distinta.

14 Nas palavras de Broome, seguir uma regra é "agir de acordo com uma disposição simples para agir de uma maneira particular e que pareça correta em relação à regra" Ele afirma que ao escolher uma regra a seguir a pessoa também escolhe uma disposição de agir que lhe parece correta (BROOME, 2014, sec. 2).
} 
tação da disposição de seguir regras inferenciais não envolve uma intenção de nossa parte, a inferência não pode se apresentar com um tipo de ação ou atividade, como quer a Taking Condition. Ao não tratar de intenções, a explicação disposicional simplesmente não responde à pergunta básica de por que as regras de raciocínio supostamente guiam o nosso "comportamento".

Como observa Boghossian: "são as regras que seguimos que explicam porque temos as disposições que temos; por exemplo, é eu estar seguindo a regra Modus Ponens que explica porque estou disposto a fazer a inferência [da chuva]" (BOGHOSSIAN 2014, p. 14). Ou seja, sob o risco de circularidade, nossas disposições não podem explicar a si mesmas. Assim, tomar uma regra de raciocínio como sendo o caso, como estabelece a Taking Condition, deve ser mais do que a manifestação de uma disposição.

\section{Seguir regras como noção primitiva}

Se seguir uma regra não é um processo subpessoal, nem tampouco a manifestação de uma disposição, então o que seria? Para Boghossian, se quisermos preservar a visão familiar de que inferir é algo que fazemos, algo que envolve agência, a única resposta plausível é tratar a habilidade de seguir regras, a nossa capacidade racional, como um fenômeno primitivo não analisável.

Se estas considerações estão corretas, enfrentamos uma escolha difícil entre tentar explicar nossa vida mental sem algo que se pareça com a noção tradicional de raciocínio no nível pessoal, por um lado, e estar disposto a adotar a noção de seguir uma regra como um primitivo não analisável, por outro (BOGHOSSIAN, 2014, p. 17).

Ao sugerir que seguir regras é um fenômeno primitivo, não analisável, a proposta de Boghossian parece empurrá-lo para um dilema. Como em geral acontece quando se evocam noções primitivas, sua sugestão a primeira vista responde ao problema do regresso apontado por Wright. 
Porém, é difícil ver como isso possa ser possível sem que, por outro lado, se comprometa a ideia de que inferir é uma operação cognitiva que envolve conteúdos proposicionais. Se o estado intencional de seguir uma regra é um aspecto não analisável das nossas vidas cognitivas, qual é o seu conteúdo?

De acordo com a Taking Conditon, quando $\mathrm{S}$ infere $\mathrm{q}$ de $\mathrm{p}, \mathrm{S}$ forma a crença que $p$ em parte porque $S$ toma a inferência, isto é, o fato que q como evidência que $p$. No entanto, para ser racional $S$ deve tomar o fato que $q$ como evidência que $p$, inferindo essa proposição de alguma outra crença. Embora essa outra crença possa envolver verdades epistêmicas das quais se possa ter conhecimento não inferencial, ela somente poderá servir de base para uma inferência, se puder servir como evidência para uma conclusão.

Assim, voltando à inferência da chuva: ao tomar o fato de que se choveu na última noite as ruas estão molhadas $(p \rightarrow q)$ como evidência de que as ruas estão molhadas (q), S está assumindo uma proposição epistêmica (q é evidência que $p$ ) que não pode ser uma crença geral, primitiva, resultante de conhecimento não inferencial. Ela terá que ser uma crença, com um conteúdo particular, sem o qual a inferência não poderá sequer começar.

Como nota Kieran Setiya (2013, p. 187), o problema não é sobre redutibilidade, mas sobre a base racional na qual alguém toma suas premissas para suportar suas conclusões. Ou seja, para que o processo inferencial possa iniciar é preciso que se tenha uma crença particular, que é a crença de que uma premissa específica, suporta a conclusão de que $q$ é evidência que $p$. No seu sentido mais comum, crenças são estados mentais, cujo conteúdo são proposições, que são objetos particulares com condições de verdade. Portanto, se tomar q como evidência para p não é um estado representacional, que envolve uma proposição que necessita de justificação, é difícil entender o que poderia ser.

\section{Crer por razões e agir por razões}

Como já referi, a motivação de Boghossian com a Taking Condition é separar a noção de raciocínio inferencial em termos de seguir regras epistêmicas 
de uma disposição cognitiva, uma regularidade, cuja explicação, segundo ele, é meramente causal. E ele faz isso estabelecendo um padrão de correção que as premissas suportem a conclusão - que todo o agente deve obedecer para que a atitude de crer que $\mathrm{p}$ com base em q conte como uma inferência.

O problema crucial de sua proposta está em relacionar esse padrão de correção com a ação racional. Isto porque no âmbito da ação racional não precisamos tomar a relação de suporte evidencial ou qualquer outra verdade epistêmica como razão para crer a conclusão. Podemos seguir a regra sem ter qualquer razão para segui-la, mesmo quando a estamos seguindo efetivamente. Tomar a nós mesmo como agentes - como alguém que é capaz de assumir a relação de suporte entre premissas e conclusão com uma razão para crer a conclusão - simplesmente não é necessário para realizar uma inferência, nem tampouco para agir racionalmente.

Ou seja, independentemente do problema do regresso, a condição de tomar é falsa, porque nem todo raciocínio envolve crer a conclusão porque a "tomamos" como sendo suportada pelas premissas. No caso de um raciocínio prático, por exemplo, no qual derivamos uma intenção de adotar um determinado meio da intenção de alcançar um determinado fim, claramente não tomamos o conteúdo da intenção-premissa, a proposição de alcançar o fim, para suportar o conteúdo da intenção-conclusão, a proposição de adotar o meio.

E é exatamente esse tipo de raciocínio - o raciocínio prático - que temos que levar em conta se quisermos falar em ação racional. Como nota Broome, o que faz o sujeito racionar neste caso não é o fato de ele assumir que há uma relação de suporte evidencial entre o conteúdo das crenças-premissa (a proposição de alcançar um determinado fim) e o conteúdo das crenças-conclusão (a proposição que determinada ação ou atitude é o meio para aquele fim). Como ocorre tipicamente no âmbito da ação, ele simplesmente toma a intenção-premissa ela mesma. Ou seja, ele toma a atitude, a intenção ou o desejo por um fim para suportar sua conclusão, a intenção de adotar uma determinada ação, independentemente dos seus conteúdos (BROOME, 2014, p. 20). 
Ao afirmar que inferir é algo que fazemos, Boghossian sugere que tomar o fato que q para suportar nossa crença que pé, de algum modo, similar ou análogo a tomar o fato que $\mathrm{p}$ como nossa razão para agir. É a ideia, compartilhada por vários autores, de que crer por razões e agir por razões envolve uma espécie de causalidade racional comum. De acordo com essa visão, ao agir com base em $p$ tomamos o fato que $p$ como nossa razão para agir, em um sentido análogo de quando ao crer que p com base em q (com base numa inferência), tomamos o fato que q como evidência para nossa crença que $p$. Não há dúvida que há semelhanças aqui. Afinal, agimos e cremos por razões. Porém, a natureza da causação e das razões para crer e agir difere crucialmente.

Particularmente, quando um sujeito infere $B$ de $A$, a passagem de $A$ para $B$ não se reporta a um acontecimento completado, a um evento ou processo, que possa entrar em uma história causal. Ela se refere a uma condição metafisicamente estática. Crer que p com base em q é crer que p e o fato de que q é evidência que p. Como nota também Setiya (2013), essa é uma explicação que cita apenas crenças presentes. É porque S crê agora que q é evidência que $p$ que ele crê que p e não porque ele "cria" q previamente, que ele agora crê que $p$ com base em $q$.

Embora possa se parecer com um processo, que envolve se concentrar nas premissas e, posteriormente, na relação entre premissas e a conclusão, inferir resume-se a uma conjugação de crenças, sem conexão causal entre elas. Para que houvesse esta conexão teríamos que considerar que crer que $\mathrm{p}$ com base em q é um estado mental, cujo conteúdo é um fato da psicologia de $\mathrm{S}$ que o fazia crer que q previamente. Porém não é essa a explicação que se costuma dar.

$\mathrm{Se}$, no caso da crença, crer que $\mathrm{p}$ e no fato de que q é evidência que $p$ é suficiente para crer que p com base em q, no caso da ação intencional, fazer $\phi$ crendo no fato que $p$ é razão para $\phi$ não é suficiente para agir com base em p. Ou seja, a relação de embasamento neste caso vai além de uma simples conjugação da crença de que p e a ação $\phi$. É necessário que haja uma relação causal entre crença e ação. Isto porque o fato de 
se estar fazendo $\phi$ por causa de $p$ não significa que $p$ é a razão para $\phi$. Podemos estar enganados sobre a base que suporta nossa ação.

A origem contemporânea desta discussão está em Davidson (1963) sobre a relação que deve haver entre agir por uma razão e ter uma razão para agir. Como ressaltei anteriormente, ao perguntarmos por que um agente fez tal e tal, queremos dar uma razão não apenas que justifica sua ação, mas que nos diga porque ele realmente fez aquilo. Isto porque ele pode ter tido uma razão justificatória e agido, mas não por causa dela. Este "porque" precisa ser especificado causalmente para que a conexão explicativa entre razão e ação não seja uma miragem.

\section{Considerações finais}

A expectativa de Boghossian é de que com a Taking Condition se possa estabelecer uma distinção entre crer que p com base em q e o tipo de ação mental que ocorre quando alguém consciente e voluntariamente crê que p com base em q. Na sua avaliação, sem a Taking Condition perdemos a "habilidade de nos tomarmos como agentes racionais" já que "racionalidade plena" requer que endossemos nossas conclusões em um "processo autoconsciente de raciocínio" (Boghossian 2014, p. 16). Ele pensa que é justamente esta habilidade de agirmos de acordo com determinas regras de racionalidade que distingue a inferência de um mero processo de formação de crenças com base em outras crenças.

Digamos, a título de argumento, que a Taking Condition seja verdadeira, que quando alguém crê que $p$ com base em $q$, ele crê $p$ porque toma o fato que q para suportar sua crença. O que isso exatamente acrescenta ao fato de que formamos crenças com base em outras crenças e que muitas vezes fazemos isso inferencialmente? Por que o sujeito em questão para salvaguardar sua condição de agente racional teria ainda que estar sujeito a Taking Condition? Por que ele teria que ter uma crença epistêmica adicional sobre a evidência e tomá-la com sua razão para agir? 
Nada impede obviamente que consideremos a inferência como um tipo de formação de crença na qual tomamos entre nossas razões para crer a relação de suporte evidencial entre premissas e conclusão. Nada nos previne também de que em determinadas circunstâncias - em um raciocínio teórico, por exemplo - consideremos explicitamente essa relação e que possamos nos considerar "epistemicamente" ativos neste sentido. Mas isso quer dizer quando muito que formamos a crença com base em uma inferência e não que estejamos sendo ativos quando inferimos.

Há certamente outras maneiras de se sustentar a ideia de que inferir é um tipo de atividade. Pode-se dizer, por exemplo, que quando $\mathrm{S}$ crê que $\mathrm{p}$ e o fato de que q é evidência de que $\mathrm{p}$ ele está exercitando uma habilidade ou disposição racional. Porém exercitar uma habilidade ou disposição racional não é o mesmo que agir racionalmente, nem tampouco de ser ativo racionalmente. ${ }^{15}$ Pelo menos não no sentido convencional de atividade atribuído pela narrativa padrão da ação, utilizada neste trabalho. Portanto, a menos que se adote outro modelo de causação racional, que não vejo qual seria, é difícil entender como inferir possa ser uma ação cognitiva em algum sentido relevante.

\section{Referências}

ANSCOMBE, G. E. M. Intention. Oxford: Basil Blackwell, 1957.

BOGHOSSIAN, P. Content and justification: Philosophical papers. Oxford: Oxford University Press, 2008.

BOGHOSSIAN, P. What is inference?. Philosophical Studies, Dordrecht, v. 169, n. 1, p. 1-18, 2014. https://doi.org/10.1007/s11098-012-9903-X

BROOME, J. Comments on Boghossian. Philsophical Studies, Dordrecht, v. 169, n. 1, p.19-25, 2014. https://doi.org/10.1007/s11098-012-9894-7

15 Como observa Matthew Chrisman (2007): não somos agentes de todos os processos que ocorrem em nós. Assim, apenas afirmar que crer é uma atividade ou um processo não quer dizer que sejamos agentes desse processo. 
DAVIDSON, D. Actions, Reasons, and Causes, reprinted in Davidson 1980. [S. l.]: [s. n.], 1963. p. 3-20

DAVIDSON, D. Mental Events. In: FOSTER, L; SWANSON, W. (ed.). Experience and Theory. London: Humanities Press, 1970. p. 79-101.

DAVIDSON, D. Freedom to Act, reprinted in Davidson 1980. p. 63-81. 1973.

DAVIDSON, D. Essays on Actions and Events. Oxford: Clarendon Press, 1980.

GOLDMAN, A. A. Theory of Human Action. Princeton: Princeton University Press, 1970.

KAHNEMAN, D. Thinking fast and slow. New York: Farrar, Strauss, Giroux, 2011.

MATTHEWS, R. The Measure of Mind. Oxford: Oxford University Press, 2007. https://doi.org/10.1093/acprof:0so/9780199211258.001.0001

MELE, A. Motivation and Agency. Oxford: Oxford University Press, 2003. https://doi.org/10.1093/019515617X.001.0001

O'BRIEN, L. Self-Knowing Agents. Oxford: Oxford University Press, 2007. https://doi.org/10.1093/acprof:oso/9780199261482.001.0001

SETIYA, K. Epistemic Agency: Some Doubts. Philosophical Issues, Malden, v. 23, n. 1, p. 179-198, 2013. https://doi.org/10.1111/phis.12009

SOSA, E. Reflective Knowledge: Apt Belief and Reflective Knowledge. Oxford:

Oxford University Press, 2009. v. 2. https://doi.org/10.1093/acprof:0so/9780199217250.001.0001

THOMPSON, M. Life and Action. Cambridge: Harvard University Press, 2008. TURRI, J. On the Relationship Between Propositional and Doxastic Justification. Philosophy and Phenomenological Research, Malden, v. 80, n. 2, p. 312-326, 2010. https://doi.org/10.1111/j.1933-1592.2010.00331.x

VELLEMAN, D. What Happens when Someone Acts?. Mind, [S. I.], v. 101, n. 403, p. 461-481, 1992. https://doi.org/10.1093/mind/101.403.461

WRIGHT, C. Comment on Paul Boghossian, "What is inference?". Philosophical Studies, Dordrecht, v. 169, n. 1, p. 27-37, 2014. https://doi.org/10.1007/ s11098-012-9892-9 


\section{Endereço postal}

Pontifícia Universidade Católica do Rio Grande do Sul - (PUCRS)

Programa de Pós-Graduação em Filosofia

Av. Ipiranga, 6681 - Prédio $8-4^{\circ}$ andar - Sala 403.

CEP 90.619-900 - Partenon, Porto Alegre, RS - Brasil. 